\title{
The Application of the POA in College English Teaching
}

\author{
Yan Wu \\ College of Humanities and Social Sciences, Heilongjiang Bayi Agricultural University, Daqing, China \\ Email: wuyan8011@163.com
}

How to cite this paper: $\mathrm{Wu}, \mathrm{Y} .(2020)$ The Application of the POA in College English Teaching. Open Journal of Modern Linguistics, 10, 70-81.

https://doi.org/10.4236/ojml.2020.101005

Received: January 16, 2020

Accepted: February 25, 2020

Published: February 28, 2020

Copyright $\odot 2020$ by author(s) and Scientific Research Publishing Inc. This work is licensed under the Creative Commons Attribution International License (CC BY 4.0).

http://creativecommons.org/licenses/by/4.0/

\begin{abstract}
The POA, a new teaching approach proposed by professor Qiu-fang Wen is more suitable for foreign language teaching in mainland of China. The biggest characteristic of this teaching method is to design real communicative scenes under the hypothesis of "output-driven", which can arouse students' learning interest by achieving some tasks under the guidance of teachers. On the basis of this teaching method, this paper takes a unit of the textbook $i E n-$ glish One as an example to design the teaching process of this unit and summarizes some teaching reflections.
\end{abstract}

\section{Keywords}

POA, Teaching Approach, College English

\section{Introduction}

In the process of college English teaching reform in mainland of China, teachers have adopted a variety of teaching principles and approaches. From the constructivism teaching concept to the functionalism, then to communicative teaching approach and finally the production-oriented approach, compared with other subjects, foreign language teaching in China has developed more increasingly and achieved many more remarkable results. With the deepening of the reform of college English teaching, more and more college English teachers begin to combine foreign teaching approaches with their own teaching practice and improve them in practice. The domestic English teaching approaches have experienced a process from copying and imitating to independent exploration.

POA, namely production-oriented approach is an innovative foreign language teaching approach developed by Qiu-fang Wen (Wen, 2016). This indigenous theory with Chinese features designs the teaching procedures according to the 
actual situation of foreign language education in China, rather than mechanically copies the western theories. It grasps the main aspects of contradictions in classroom teaching.

\section{The Theory of the Production-Oriented Approach}

The development of the POA has gone through five stages. The first is pre-heating period from 2007 to 2013, in which "output-driven hypothesis" was advocated (Wen, 2007). The second stage is prototype period from 2013 to 2014, and the "output-driven and input-enabled hypothesis" was claimed (Wen, 2014). The third stage is formative period from 2015-2016, in which "production-oriented approach" was firstly formed by Wen (Wen, 2015). The fourth stage is revision period from 2016 to 2017 (Wen, 2017). And the fifth stage is re-revision period from 2017 to 2018 (Wen, 2018).

The POA blends the curriculum theory and the theory of second language acquisition which highlights the leading role of a teacher and overcomes the disadvantages of these two theories according to the situation of China's foreign language education. It can solve the problems of separation of study and application and low efficiency in foreign language teaching. It not only emphasizes on the producing, but the product in learning. Figure 1 illustrates the theoretical system of POA.

The POA theoretical system consists of three components: teaching principles, teaching hypotheses, teacher-mediated and teacher-student collaborative teaching process.

\subsection{Teaching Principles}

Combing the excellent researches of foreign language teaching theories, "learning-centered" the POA challenges the teaching model of "learner-centered". The

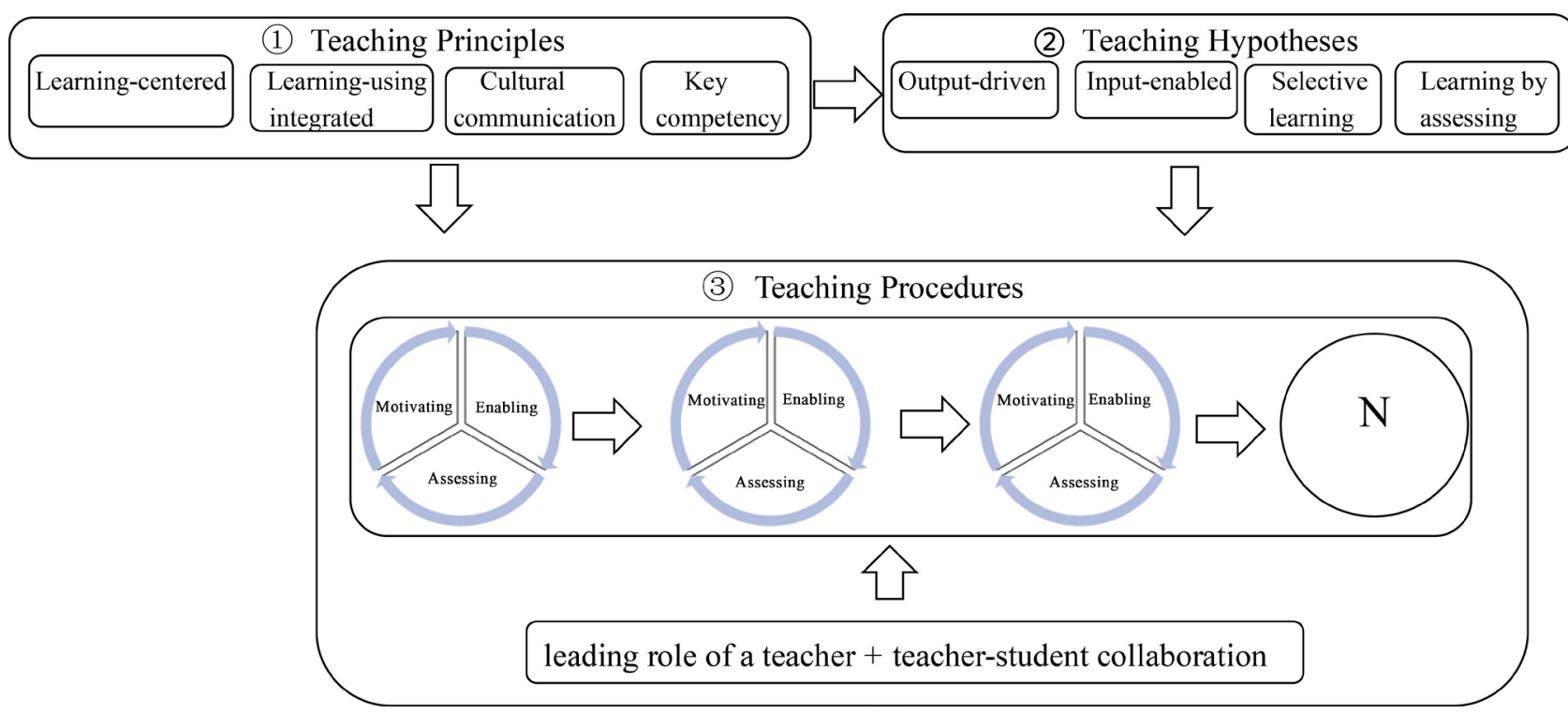

Figure 1. The fifth stage: re-revised POA (cited from Wen, 2018). 
new teaching model enables students to choose materials and methods which are suitable for their own needs to learn and to obtain the guidance of learning strategies from teachers. They are active participants and the subjects in foreign language teaching.

\subsubsection{Learning-Centered Principle}

Learning-centered principle advocates that teaching must achieve the teaching objectives and promote the effective learning. Therefore, $\mathrm{POA}$ is more concise and more accurate than the other teaching principles in reflecting the essence of education. It focuses on what students can learn in classroom teaching. There are many classroom activities which can be chosen to serve different teaching objectives, such as, group discussion, individual presentation, etc. The key point is that teachers choose the best form to achieve the teaching objectives.

\subsubsection{Learning-Using Integrated Principle}

In traditional foreign teaching language teaching, teachers always take teaching text as the goal of teaching objectives, rather than as a tool to develop students' comprehensive use of English. There is large time lag between input and output of language. The content of the textbooks has just been processed or even have not yet finished, they must enter the next new unit. There is no enough time to cultivate their abilities to produce the language.

In the theoretical system of POA, "learning" refers to the input learning, including listening and reading. "using" refers to "output", including speaking, writing and translation (Wen, 2016). POA advocates that there is a close combination between input learning and output application. It can avoid the disadvantages of "textbook-centered", "text-first" and "separation of learning and using" in teaching practice.

The principle of "learning-using integrated" in POA theory advocates that all the language teaching activities are closely linked with language application. So that there is no boundary between "learning" and "using" and they are integrated in teaching. The texts are no longer learned by students, but as means to fulfil the tasks.

\subsubsection{Cultural Communication Principle}

College English is a part of humanistic education of higher education which has instrumental and humanistic functions. As far as its instrumental function, the main purpose of college English is to further improve students' abilities of listening, speaking, reading, writing and translating. And in the aspect of humanistic function, one of its main tasks is intercultural education. The core of humanity is "people-oriented" to develop human values. It pays attention to students' comprehensive qualities training and all-round development.

Cultural communication principle is to develop learners to correctly handle the relationship between the target language culture and the learner's native culture. Language and culture are closely linked, so the issue of cultural education cannot be avoided in teaching. In classroom teaching, cultural learning is 
integrated in language teaching.

\subsubsection{Key Competency Principle}

Professor Wen believed that foreign language teaching must cultivate the key abilities which everyone needs in the $21^{\text {st }}$ century (Wen, 2018). And the key competency is the ability that can solve complex problems in an uncertain complex situation. It contains four core qualities: language ability, cultural literacy, thinking quality and learning ability.

\subsection{Teaching Hypotheses}

The POA proposes four teaching hypotheses: output-driven hypothesis, input-enabled hypothesis, selective learning hypothesis, and learning by assessing hypothesis.

\subsubsection{Output-Driven Hypothesis}

Output-driven hypothesis of POA reverses the sequence of "input" and "output" in the traditional teaching. Namely it lets learners attempt to "output". The process of achieving the product first makes students aware of the difficulties of "output", and then teacher provides them with some relevant "input" and analyzes difficulties facing in the process of it, to assist students effectively absorb, digest and use the "input" to achieve the tasks.

\subsubsection{Input-Enabled Hypothesis}

Input-enabled hypothesis refers to input materials which are intended to serve specific output objectives. Input-enabled hypothesis and output-driven hypothesis are closely related in POA. In classroom teaching, after the output-drive process, there must be some corresponding tasks which can effectively facilitate the completion of the output.

\subsubsection{Selective Learning Hypothesis}

"Selective learning means that the learner chooses to learn only what is useful for the assigned productive activity" (Wen, 2016). It means that goal-oriented learning is more efficient than holistic learning. In the information age, there are a large number of various learning materials. When facing the limited time, students need to choose the learning materials according to the actual needs and situations.

\subsubsection{Learning by Assessing Hypothesis}

The hypothesis holds that the combination of assessing and learning can achieve better teaching effect than the separation of them. POA believes that the assessment, learning and teaching should be combined. And the assessment is the key in language learning and the essential part of the teaching cycle chain.

\subsection{Teaching Procedures}

There are three teaching phases in POA, the first phase is motivating. The second part is enabling and the third stage is assessing. Teachers play the me- 
diators in all these three phrases. They are guiders, designers and scaffolders in the teaching process. Each teaching unit consists motivating-enabling-assessing. There are a number of teaching circulatory chains in teaching.

\section{The Application of the POA in College English Teaching}

In this part, the second unit of the textbook iEnglish One was taken as an example to design the teaching procedures based on the POA. The topic of this unit is "The Magic of Words". It contains two texts, iExplore 1 English is a crazy language and iExplore 2 An open letter to the Chinese language which promote language learning and prepare the perspectives to complete the product. 60 freshmen from Chinese language and literature were involved in the teaching experiment. After the teaching experiment, as a practical teacher, the author collected feedback and evaluations from students on the POA teaching theory through interviews and as well as the author's teaching reflections based on her classroom observation.

\subsection{Teaching Objectives}

The teaching objectives can be divided into language and cultural objectives. The cultural goals are to enhance students' awareness of the importance of learning a foreign language, to understand the difficulties in learning the Chinese language for non-native speakers, to identify the differences and some unique features and usages between English language and Chinese language and to exchange their unique experiences of language learning. The language objectives include to grasp the basic words and phrases expressions which can be used in tasks, to learn usages of transition words, to express their attitudes and points of view fluently and methodically, to master the structural characteristics of suggestive speech.

\subsection{Teaching Task}

Students should be able to complete the unit task after studying the two texts. The final task of this unit is to give a 10-minute presentation to some overseas students who are learning Chinese. The presentation focuses on the features of the Chinese language and some suggestions on how to learn it well.

When designing the teaching process, the task can be divided into some sub-tasks to help students gradually achieve the teaching objectives. Three tasks are offered by teacher. Task 1, students list the features of English and some difficulties in their experiences of English learning after studying iExplore 1. Task 2, students summarize the features of Chinese language and some difficulties which overseas students may encounter to learn it according to iExplore 2. Task 3 , students learn how to give a proper presentation for non-native speakers to learn Chinese language.

\subsection{Teaching Procedures}

According to the output task, the structure of this unit can be divided into three 
parts according to the theory of POA. The whole structure of this unit is showed in Figure 2.

\subsubsection{Motivating}

Motivating is achieved by iPrepare which outputs the presentation of communication scenarios and stimulates learners' learning motivation. Students carry out selective learning to choose to learn the knowledge of language and skills which needed to complete the output tasks. In this stage, Teacher introduces the output task and explains how to complete the output task step by step. With the discussions of two texts, students not only have learned about the special usages in English, but also understood the difficulties non-native learners might face in learning Chinese.

Students try to find out the five effective ways to learn a new language mentioned in the video clip which learned before class and they will be encouraged to explore and recommend more effective ways to learn Chinese language to non-native speakers based on their own experience of learning English. Students will experience that it is not easy to complete this challenging task, which will stimulate their enthusiasm to complete the task and enhance their learning motivation in the following studying.

\subsubsection{Enabling}

The second phase is "enabling" which guided by teachers to lead students to learn a series teaching steps. It is the essential part of the teaching in POA. In this stage, teacher first sets up scaffolding for students through online courses, providing them with input in language, knowledge, values, emotions and other aspects. Then the students will be led to study selectively and sort out the input materials from three aspects: content, language form and language structure. In this process, teachers consciously reduce their roles of scaffolding, and gradually improve students' sense of responsibility for learning.

Through reading the texts and doing exercises, students will be equipped with relevant information, language and structure. There are some useful expressions

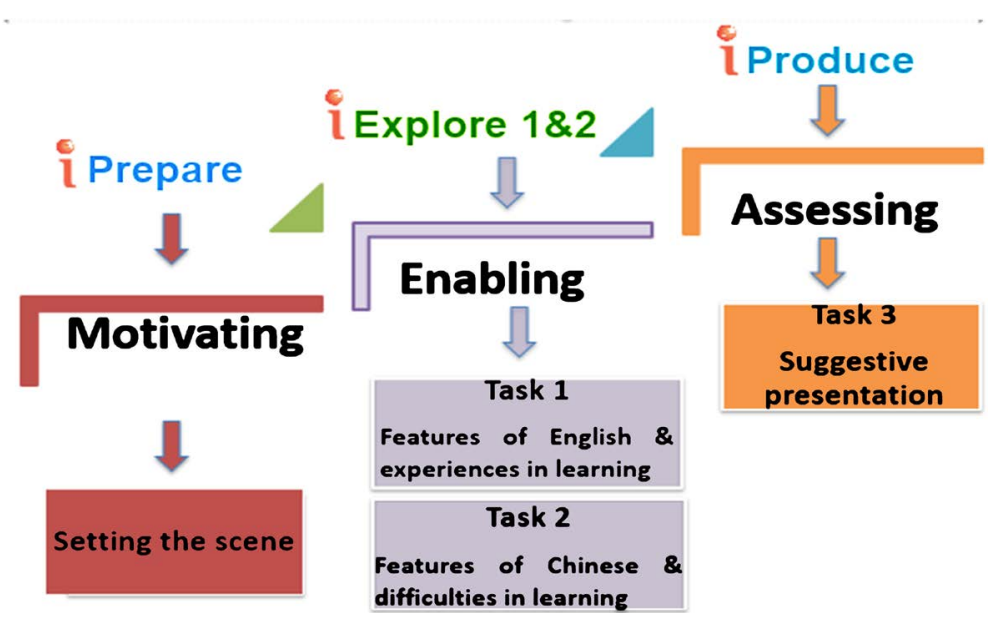

Figure 2. The structure of unit. 
in the two texts, such as, "The most widely spoken language in the history of our planet." "Language is like the air we breathe. It's invisible, inescapable, indispensable, and we take it for granted." "What I mean to say is that you are difficult. You're hard to read, and all too often I just don't understand you." "I'll work hard in my class, and more importantly, we'll be together as much as possible outside the classroom." All of these expressions can be used in the final product.

After building their language, teacher scaffolds students in the critical thinking process to list the differences between English and Chinese in the following steps.

Step 1 developing the ideas

Task 1: to list the features of English and difficulties in learning

The text in iExplore 1 is a humous piece of writing about the "crazy" English language. Its "craziness" is probably part of the reason why English is difficult to learn. Through reading the text, students will find that there are some paradoxes expressions in English which is hard to understand. For example, "drive in a parkway, park in a driveway", etc. And some words or expressions are seemingly opposite in meaning but referring to the same thing, and vice versa. These usages are in fact a natural part of the language, but difficult for Chinese students to understand them.

Task 2: to summarize the features of Chinese

The author of the iExplore 2 complains about the difficulties he met in learning Chinese. But English is not alone as a difficult language to learn. In fact, many non-native learners complain that Chinese is the most difficult language. Teacher can encourage students to exchange their troubles and experiences of language learning with each other to collect enough perspectives and suggestions for the task of iProduce. For instance, teacher gives a question for students to talk about, "Based on your experiences of English learning, what are the different features between English and Chinese?" to guide students to brainstorm some "crazy" expressions in Chinese to have a better understanding of the difficulties in learning the Chinese language for a non-native learner.

Students are guided to work in pairs and make a list of the different features between English and Chinese in the aspects of phonetics, lexis, grammar. Students need to identify the characteristics of the Chinese language through comparing with English, and find out enough examples to illustrate its characteristics. For example, the first feature, English is a stress-based language, while Chinese is a tonal language. There are four tones, and different tones indicate different characters and meanings. The second feature, there is no morphological changes in grammar. English emphasizes the structure and grammar, while Chinese focuses on the meaning. Chinese grammar lacks morphological changes in person, tense, gender, and number in the strict sense. The third feature, Chinese characters are unique among the languages in the world. They originated from hieroglyph. 
Step 2 giving some suggestions

After comparing the characteristics of the two languages, each group is asked to give some effective suggestions based on the acquired knowledge to the overseas students with their Chinese learning. In this process, students are encouraged to use the words and expressions highlighted in exercises to describe their language-learning experiences. For instance, suggestion 1: Spend at least a month just mastering the basic phonetics of this language. Suggestion 2: Practice makes perfect. Keep practicing listening, reading, speaking and writing as much as you can. Suggestion 3: Learn some basic conversational phrases and grasp every opportunity to talk with native speakers whenever possible.

Task 3: to organize the presentation

In this part, teacher needs to develop students' pragmatic competence of giving suggestions and stating reasons, to guide students to finish the project by referring to the features of the English and Chinese languages and suggestions on how to learn a new language, which are summarized by students.

"How do you suggest a non-native speaker to learn Chinese well?" should be considered by students. The structure of the presentation with the help of the outline (Figure 3 ).

Students draft a detailed outline of the presentation and remind them that further reading of the texts can help them get ideas and expressions for their presentations, to improve logic and polish language.

\subsubsection{Assessing}

Motivating is the startup of a new unit; enabling is the primary stage of teaching and the assessing is sublimating of teaching. iProduce focuses on the output task which students solve the practical problem by what they have learnt in the unit to realize the combination of learning and application. In this stage, teacher evaluates students' learning effect in the process of selective learning and output task exercise based on the learning objectives of the unit. The multi-dimensional evaluations are implemented to guide students to discover, conclude, question and summarize through self-assessment and peer-assessment, so as to help students complete the transition from old knowledge to new knowledge. In this phase, students' language products are assessed.

Production-oriented approach focuses on the comparison between the expected learning outcomes and actual learning outcomes, rather than the comparison

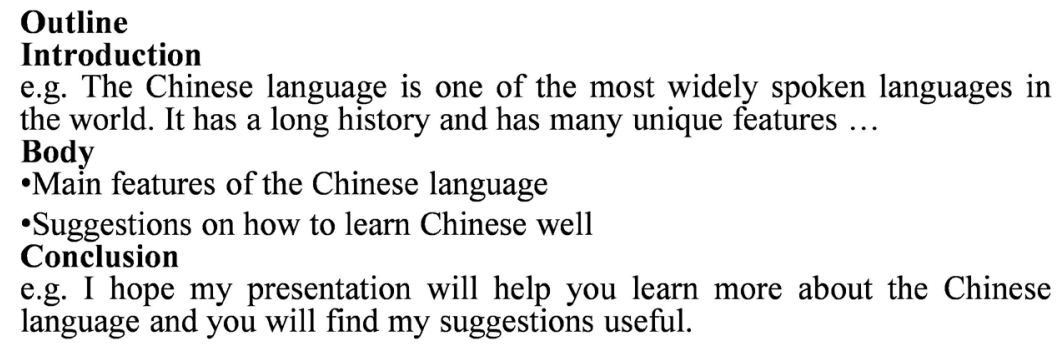

Figure 3. (Cited from iEnglish 1, p41). Wang \& Wen (2015). 
between students. According to the checklist of expected teaching results, the corresponding evaluation results are divided into "poor/ok/good" (Table 1) from the aspects of content, language and structure. By encouraging students to fill in the information according to their actual situation, teacher can get intuitive data feedback and know whether the learning effect of this unit has been achieved, so as to continuously improve the teaching.

\section{Teaching Feedback}

The teaching of this unit lasted for two weeks, 8 periods in total. The teaching feedback contains two parts: students' feedback and teacher's teaching reflection.

\subsection{Students' Feedback}

After the teaching experiment, the author learned about the students' feelings and their evaluations about teaching through interviews.

\subsubsection{Feedback on the Teaching Approach}

"Various sub-tasks improve classroom efficiency and help us make full use of class time."

"The class is fast-paced, and I am always ready to answer questions, unlike in the past, when it was my turn to speak."

"It is difficult to adapt to the new teaching method immediately."

"I didn't evaluate my answers at all and try to revise them."

"It is almost difficult for me to know where to start in the evaluation process."

It can be seen from students' feedback that POA can promote them actively and effectively to participate in classroom activities. However, some students have the adaptation problem of teaching form transformation, which requires teachers to play the role of scaffolding.

\subsubsection{Benefit of Learning}

"I no longer have to mechanically read the answers and memorize the templates, but to think, I need to concentrate my attention on learning."

"My task in class is heavier than before. By using the input materials, I can choose the words and sentences by myself and organize the answers. The method improves my ability of thinking in English and that of textual organization."

Table 1. Criteria for self-assessment and peer-assessment.

\begin{tabular}{|c|c|c|c|c|c|}
\hline & checklist & poor & ok & good & comments \\
\hline \multirow[t]{2}{*}{ Content } & well-developed and informative content & & & & \\
\hline & a wide range of appropriate vocabulary & & & & \\
\hline \multirow[t]{2}{*}{ Language } & appropriate cohesive devices & & & & \\
\hline & flexible use of sentence structures & & & & \\
\hline Structure & $\begin{array}{l}\text { a well-structured presentation with clear } \\
\text { topic sentences and supporting details }\end{array}$ & & & & \\
\hline
\end{tabular}


"In class, the teacher will not give us the answers directly, we learn to organize the answers by ourselves."

In the face of new problems, students should collect vocabulary and language structures needed to answer the questions by themselves. They can also reuse the knowledge they have learned before and express their ideas more clearly. Learning objectives and tasks are clear for each student, and the feedback of each task is instant.

\subsection{Teaching Reflection}

\subsubsection{The Shift of Teacher's Role}

College English teaching in mainland of China has been in the process of reform and innovation over 70 years. And teacher's role has been changed from the traditional teacher-centered model to a scaffolder in learning-centered teaching pattern. POA urges teachers shift their roles in teaching as soon as possible in order to get fairly good teaching effect. The role of a teacher determines the principles of the classroom organization and the teaching methods. The traditional education system is teacher-centered teaching pattern. Teacher has always been seen as a helper, a consultant facilitator. In this case, teaching and learning are in a separate relationship. The teacher is the ruler of the classroom who decides the content, mode and method of teaching. Although students have the abilities to study by themselves, teachers are indispensable as the main interactive objects and mediators in the process of constructing. The role of a teacher in the POA teaching model has been transformed to become a mentor, a designer, a leader, an organizer and a motivator of learning interest. Teacher not only provides the best language learning environment for students, but also plays an important intermediary role in guiding, assisting, promoting and encouraging learners' language learning. On the one hand, it emphasizes the subject status of students, and on the other hand, teacher's role is becoming diversified.

\subsubsection{Selective Learning}

The "selective learning hypothesis" holds the view that goal-oriented learning is more efficient than "holistic learning". With input materials, students carry on the "selective learning", such as the key words, collocations, the functional expressions, text organizations and so on, in the aspects of the language skills, the perspectives, and the structure of the texts in order to complete the unit output task to finally bridge the gap between learning and applying.

POA advocates that to select the required language, content and discourse structure from the input materials according to the output objectives. And the input materials that are not urgently needed for the output can be reduced the requirements in learning.

\subsubsection{Multidimensional Assessment}

Different from the traditional single and static assessment, the POA emphasizes multiple assessments, such as from the aspects of "knowledge and ability", "for- 
mation and termination", "online and offline", etc.

The POA approach has realized the multidimensional evaluations. In the process of peer-assessment, students take the initiative to appreciate each other's works and learn from each other. In the process of teacher-assessment, formative evaluation is the most important method in task-based teaching. Teacher gives instant feedback on students' preparation and performance in class, which can effectively motivate and arouse students' learning interest. During the process of self-assessment, students need to evaluate themselves from the aspects of team work, class participation and assignments. In this way, guidance and incentives of the evaluations can come into play, and can promote all-round and multi-angle self-assessment. Students are aware of their strengths and weakness. They recognize the benefits of cooperative learning and the cultivation of good study habits.

\section{Conclusion}

With its unique perspectives and innovation, the theoretical system of POA has attracted more and more College English teachers' attention. How to motivate students' learning enthusiasm and how to make the class-learning more effective are problems faced by teachers. "Learning-centered" principle of the POA is a completely innovative method which is more suitable for Chinese students to learn English. It emphasizes the importance of input and output and leads the teachers to think about how to transform the teaching from traditional text-centered teaching model to focusing on the production of learning. It puts forward corresponding requirements for the teachers and students and emphasizes on teacher-student cooperation. It constructs the teaching hypothesis of "output-driven, input-enabled" and realizes "learning-using integrated" teaching principle to provide the effective solutions to the problems of foreign language teaching in China.

\section{Acknowledgements}

This paper was supported by the general education research project of Heilongjiang Provincial Department of Education in 2019: "The Blended Learning Course Design of College English Based on Chinese Cultural Transmission", Project No. SJGY20190471.

\section{Conflicts of Interest}

The author declares no conflicts of interest regarding the publication of this paper.

\section{References}

Wang, S. R. \& Wen Q. F. (Eds.) (2015). iEnglish One. Beijing: Foreign Language Teaching and Research Press.

Wen, Q. F. (2007). Output-Driven and Problem-Driven Hypotheses: Reforms on the 
Curriculum and Teaching Methods for English Majors' Programs in a New Century. The $1^{\text {st }}$ National Forum of Chairs of English Departments, Shanghai, 12 May 2007.

Wen, Q. F. (2014). Output-Driven, Input-Enabled Hypothesis: A Tentative Theory of Foreign Language Classroom Instruction for University Students. Foreign Language Education in China, 2, 1-12.

Wen, Q. F. (2015). Developing a Theoretical System of the Production-Oriented Approach in Language Teaching. Foreign Language Teaching and Research, 4, 547-558.

Wen, Q. F. (2016). The Production-Oriented Approach to Teaching University Students English in China. Language Teaching, 4, 526-540. https://doi.org/10.1017/S026144481600001X

Wen, Q. F. (2017). Chinese Features Displayed in the Production Oriented Approach. Modern Foreign Languages, 5, 348-358.

Wen, Q. F. (2018). Production-Oriented Approach in Teaching Chinese as a Second Language. Chinese Teaching in the World, 3, 387-400. 